\title{
Effect Of Peppermint Essence On The Pain And Anxiety Caused By Intravenous Catheterization In Cardiac Patients: A Randomized Controlled Trial
}

This article was published in the following Dove Press journal:

Journal of Pain Research

\author{
Fatemeh Akbari ${ }^{1}$ \\ Mansour Rezaei ${ }^{2}$ \\ Alireza Khatony $\mathbb{( D}^{3}$ \\ 'Students Research Committee, \\ Kermanshah University of Medical \\ Sciences, Kermanshah, Iran; ${ }^{2}$ Social \\ Development and Health Promotion \\ Research Center, Kermanshah University \\ of Medical Sciences, Kermanshah, Iran; \\ ${ }^{3}$ Clinical Research Development Center, \\ Imam Reza Hospital, Kermanshah \\ University of Medical Sciences, \\ Kermanshah, Iran
}

Background: The effects of the peppermint essence on the pain and anxiety caused by intravenous catheterization have not been studied yet. The aim of this study was to determine effect of inhaling peppermint essence on the pain and anxiety.

Methods: In this study, 80 cardiac patients were selected through convenient sampling and randomly allocated to aromatherapy and control groups. Data gathering tools were numeric pain rating scale and visual analogue scale for anxiety. The aromatherapy and control groups received inhaled aromatherapy with peppermint essence and distilled water, respectively.

Results: Mean severity of the pain in the aromatherapy and control groups was $2.95 \pm 0.98$ and $3.42 \pm 1.33$, respectively. The difference was statistically significant ( $p=0.048$ ). The mean score of anxiety before the intervention in the aromatherapy and control groups was 3.75 \pm 1.08 and $4.70 \pm 1.43$, respectively; these figures after the intervention were $2.32 \pm 0.97$ and $2.10 \pm 1.42$, respectively. The two groups were not significantly different before and after the intervention in terms of the level of anxiety. However, the level of anxiety before and after the intervention was significantly different in each group $(p<0.001)$.

Conclusion: Aromatherapy attenuated the pain and anxiety caused by intravenous catheterization. Before catheterization, peppermint essence aromatherapy is recommended.

Keywords: anxiety, aromatherapy, intravenous catheterization, pain, peppermint

\section{Introduction}

Intravenous catheterization provides a pathway to inject liquid, blood products, and medicine to patients. ${ }^{1,2}$ The procedure is one of the most common invasive methods that may cause discomfort, anxiety, and pain in most of the patients. ${ }^{3,4}$ The pain and anxiety are more serious when the peripheral veins are not easy to access and attempts to access the veins fail frequently. ${ }^{5,6}$ There are evidence that failed catheterization may cause more pain and discomfort in patients. ${ }^{7,8}$ Among the interventions perform to soothe the pain and anxiety caused by intravenous catheterization, cryotherapy, EMLA topical anesthetic cream, and local anesthesia are notable. Along with the effectiveness of these methods, the side effects like allergic responses and delay in inducing the effect are also notable. ${ }^{9,10}$ Today, complementary medicine has drawn a great deal of attention among researchers. ${ }^{11}$ Inhalation aromatherapy is one of the complementary medicine that can be effective in pain and anxiety management. ${ }^{12-14}$ Inhalation of aroma stimulates the nervous system and by secreting endorphin and noradrenaline, the neurons induce positive mental and physical effects. ${ }^{15}$ Since there is a direct relationship between pain and anxiety, aromatherapy can attenuate the
Correspondence: Alireza Khatony Nursing Department, School of Nursing and Midwifery, Doolat Abaad,

Kermanshah, Iran

Tel/fax +98 8338279394

Email Akhatony@gmail.com 
anxiety caused by pain through stimulating the limbic system. Aromatherapy may also decrease anxiety through decreasing the level of cortisol and increasing serotonin. ${ }^{16}$ There are evidence that inhaling essential oil may trigger the secretion of endorphin and attenuate pain and anxiety in return. ${ }^{17}$

Peppermint with the scientific name Mentha piperita is one of the essences used for aromatherapy. Mentha piperita is an aromatic herb with analgesic and tranquilizing effects. The analgesic effect of peppermint can be due to its main compounds like Carvone, Limonene, and Menthol. ${ }^{18,19}$ Menthol in peppermint affects Kappa Opioid receptors and soothe the pain in return. In addition, menthol is effective in soothing the pain through increasing the stimulation threshold of cells and decreasing synoptic stimulations and transmits. ${ }^{20}$

There is no consensus about the effects of aromatherapy with peppermint on pain and anxiety so that some believe in its effectiveness ${ }^{18-21}$ and some argue that it is ineffective. ${ }^{22,23}$ It appears that more studies are needed in this area. Taking into account that all the previous studies in this area have focused on surgery, cardiac diseases, stress, post-operative pains, low back pain, and neck pain and that there is no study on the pain and anxiety caused by intravenous catheterization, the present study is an attempt to assess the effects of inhalation of peppermint aroma on the pain and anxiety caused by intravenous catheterization in cardiac patients.

\section{Methods}

\section{Research Hypothesis}

Peppermint inhalation aromatherapy can soothe the pain and anxiety caused by intravenous catheterization in cardiac patients.

\section{Study Design}

The study was carried out as a randomized controlled trial study with control group in 2017 from December 2016 to June 2017.

\section{Sample And Sampling Method}

The study population was comprised of all cardiac patients hospitalized in Imam Ali Hospital affiliated with Kermanshah University of Medical Science (KUMS). The sample size was determined equal to 32 based on the previous studies ${ }^{3,24}$ (level of confidence $=95 \%$, test power $=90 \%$ ). To have a higher test power, 40 patients were selected for each group by convenience sampling and allocated to the groups by random allocation. Inclusion criteria were full consciousness, reading and writing literacy, age range at $18-65$, not pregnant (in case of women), no drug addiction or smoking habits (self-statement), not using sedatives and analgesics over the past $6 \mathrm{hrs}$ (self-statement), no chronic respiratory disease such as asthma and allergy (self-statement), no history of mental and neurological diseases (self-statement), and no olfaction impairment. To examine olfaction in the subjects, three drops of Rose Damascena were poured on a cotton ball and used to check olfaction in the patients. Reluctance to participant and failure of first attempt to find the vein were the exclusion criteria. The subjects that met the inclusion criteria entered the study through convenient sampling and grouped into control and intervention groups based on random block method. That is, each pair of patients would be allocated randomly to one of the double blocks. The double blocks were AB and BA. The researcher would allocate the double blocks to each pair of patients. In the case of "AB" block, patient one would be allocated to the intervention group and patient two would be allocated to the control group and vice versa for the BA block. The process was continued until all the participants were allocated. It is notable that the blocks were designed by a statistician and the first author performed the allocation process.

\section{Instruments}

Data gathering tools included numeric pain rating scale (NPRS) and visual analogue scale for anxiety (VAS-A). In addition, a personal information form including age, sex, body mass index, job, education, marital status, diagnosed disease, history of hospitalization, and history of intravenous catheterization was used.

To measure the experienced pain, NPRS was used, which is a $10 \mathrm{~cm}$ ruler marked from 0 (no pain) to 10 (the highest imaginable pain). Validity and reliability of the tool have been examined and supported by several studies. $^{25,26}$ To measure anxiety, VAS-A tool was used, which is also a $10 \mathrm{~cm}$ ruler marked from 0 (no anxiety) to 10 (the highest imaginable anxiety). Different studies have supported the reliability and validity of the tool. ${ }^{27-29}$

\section{Intervention}

The study was carried out in Imam Ali Hospital affiliated with KUMS. The hospital is the largest heart hospital in the west of Iran. The subjects were briefed about the objectives and all of them signed a written form of 
consent. Afterwards, the subjects were allocated to control and intervention groups. The former received peppermint essence inhalation aromatherapy and the control group received distilled water inhalation aromatherapy (placebo). The peppermint essence using in the study was $100 \%$ pure (Barij Essence Pharmaceutical Co. Iran).

Participants of the both groups first filled out the personal information form and VAS-A. Then, peppermint inhalation aromatherapy was performed in the intervention group. To this end, three drops of peppermint were poured on a piece of cotton and attached to the collar of the subjects' cloth $10 \mathrm{~cm}$ from their nose. Inhalation continued for $5 \mathrm{mins}$. The same process was carried out for the control group with three drops of distilled water (placebo). After the intervention, intravenous catheterization was performed by the researcher (first author) for all the subjects and they asked to fill out VAS-A and NPRS. Identical angiocath $(20 \mathrm{G})$ was used for all the subjects in the elbow area. Figure 1 illustrates the process of study.

\section{Data Analysis}

Data were analyzed using the 16th version of the Statistical Package for Social Sciences (SPSS v.18.0; SPSS Inc., Chicago, IL, USA). The Chi-square test was used to compare the demographical variables (age, sex, education, marital status, diagnosis of disease, history of hospitalization, and history of catheterization). Moreover, to examine the distribution of the quantitative variables (age, BMI, pain, and anxiety), Kolmogorov-Smirnov (KS) test was used. The results showed that pain and anxiety variables were
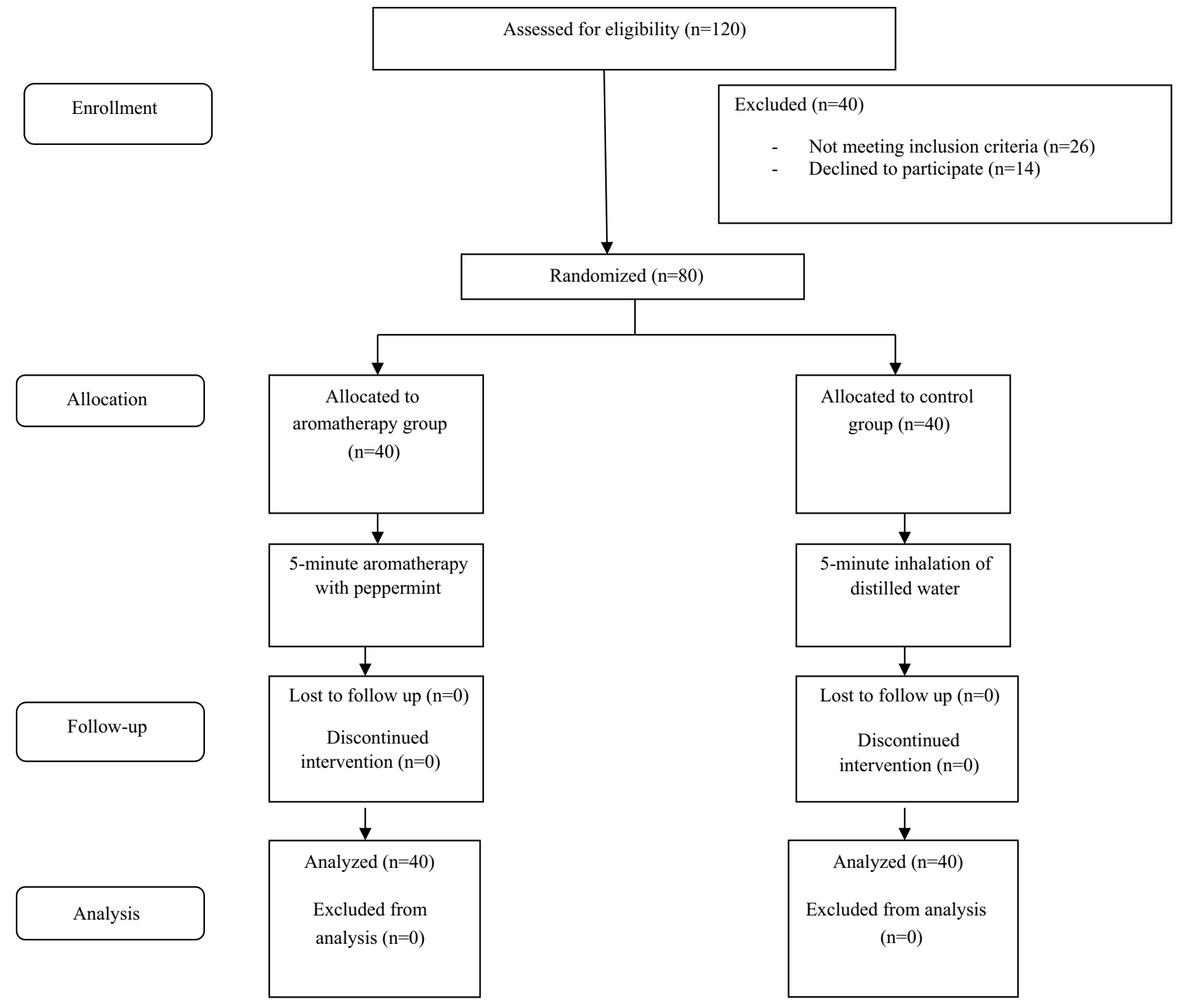

Figure I CONSORT diagram of study process. 
not distributed normally. To compare anxiety before and after the intervention, Wilcoxon signed-rank test was used. To compare the level of anxiety before the intervention in the control and experiment groups, Mann-Whitney $U$-test was used. The same test was used to compare the level of anxiety and pain before the intervention in the two groups. Significance level was set at $<0.05$.

\section{Ethical Considerations}

This trial was conducted in accordance with the Declaration of Helsinki. The Ethics Committee of KUMS confirmed the study under the code: KUMS.REC.1395.570. The study also was registered in Iranian Registry of Clinical Trials under the code IRCT201612124736N20. As to the nature and objectives of the study, all the participants were briefed and they were ensured about the confidentiality of their information. All the subjects signed a written form of informed consent.

\section{Results}

Mean and standard deviation of age of the participants was $55.1 \pm 8.1$ years and the age group 54-65 had the highest frequency $(n=52,65 \%)$. More than one half of the subjects $(n=48,60 \%)$ were men, had elementary education $(n=44$,
$55 \%)$, suffered from coronary artery diseases $(n=51,63.7 \%)$, and had a history of hospitalization for coronary diseases $(\mathrm{n}=59,73.8 \%)$. All the participants were married and had a history of angiocath procedure (Table 1).

The two groups were homogenous in terms of personal variables (gender, BMI, job, marital status, disease diagnosis, history of hospitalization, and history of catheterization) except for age. The mean scores of pain severity caused by catheterization in the intervention and control groups were $2.95 \pm 0.98$ and $3.42 \pm 1.33$ (out of 10), respectively. Based on Mann-Whitney $U$-test result, there was a significant difference between the two groups in terms of the intensity of pain after the intervention ( $p=0.048$ ) (Table 2). Before the intervention, the mean scores of anxiety in the intervention and

Table 2 Comparison Of Pain In Aromatherapy And Control Groups

\begin{tabular}{|l|l|l|l|}
\hline Pain & $\begin{array}{l}\text { Aromatherapy } \\
\text { Group }\end{array}$ & $\begin{array}{l}\text { Control } \\
\text { Group }\end{array}$ & Difference \\
\hline $\begin{array}{l}\text { Mean } \pm \text { SD } \\
95 \% \mathrm{Cl}\end{array}$ & $2.95 \pm 0.986$ & $\begin{array}{l}3.425 \pm 1.338 \\
2.635-3.265\end{array}$ & $\begin{array}{r}-0.475 \pm 0.249 \\
-1.067-0.117\end{array}$ \\
\hline Test result & $Z^{\mathrm{a}}=-1.979, P=0.048$ & \\
\hline
\end{tabular}

Note: ${ }^{a}$ Mann-Whitney U-test.

Abbreviations: $\mathrm{Cl}$, confidence interval; SD, standard deviation.

Table I Demographic Characteristics Of Study Groups

\begin{tabular}{|c|c|c|c|c|}
\hline \multicolumn{2}{|l|}{ Variables } & \multirow{2}{*}{$\begin{array}{l}\text { Aromatherapy } \\
\text { Group, n (\%) } \\
\text { I (2.5) } \\
7(17.5) \\
32(80)\end{array}$} & \multirow{2}{*}{$\begin{array}{l}\text { Control Group, n (\%) } \\
4(10) \\
16(40) \\
20(50)\end{array}$} & \multirow{2}{*}{$\begin{array}{l}p \text {-value } \\
<0.001\end{array}$} \\
\hline Age (years) & $\begin{array}{l}28-40 \\
4 I-53 \\
54-65\end{array}$ & & & \\
\hline Sex & $\begin{array}{l}\text { Male } \\
\text { Female }\end{array}$ & $\begin{array}{l}24(60) \\
16(40)\end{array}$ & $\begin{array}{l}24(60) \\
16(40)\end{array}$ & NS \\
\hline Marriage & $\begin{array}{l}\text { Single } \\
\text { Married }\end{array}$ & $\begin{array}{l}- \\
40(100)\end{array}$ & $\begin{array}{l}- \\
40(100)\end{array}$ & NS \\
\hline Education & $\begin{array}{l}\text { Primary school } \\
\text { Secondary/high school } \\
\text { Diploma }\end{array}$ & $\begin{array}{l}29(72.5) \\
5(12.5) \\
6(15)\end{array}$ & $\begin{array}{l}15(37.5) \\
9(22.5) \\
16(40)\end{array}$ & $<0.001$ \\
\hline History of hospitalization & $\begin{array}{l}\text { Yes } \\
\text { No }\end{array}$ & $\begin{array}{l}31(77.5) \\
9(22.5)\end{array}$ & $\begin{array}{l}28(70) \\
12(30)\end{array}$ & NS \\
\hline Occupation & $\begin{array}{l}\text { Housekeeper } \\
\text { Self-employed } \\
\text { Retired } \\
\text { Farmer }\end{array}$ & $\begin{array}{l}15(37.5) \\
15(37.5) \\
6(15) \\
4(10)\end{array}$ & $\begin{array}{l}14(35) \\
12(30) \\
9(22.5) \\
5(12.5)\end{array}$ & NS \\
\hline Disease diagnosis & $\begin{array}{l}\text { Coronary artery disease } \\
\text { Heart failure } \\
\text { Myocardial infarction }\end{array}$ & $\begin{array}{l}25(62.5) \\
7(17.5) \\
8(20)\end{array}$ & $\begin{array}{l}26(65) \\
9(22.5) \\
5(12.5)\end{array}$ & NS \\
\hline
\end{tabular}

Abbreviation: NS, non-significant. 
control groups were $3.87 \pm 1.04$ and $3.47 \pm 1.43$ (out of 10), respectively. After the intervention, these figures were 2.32 \pm 0.97 and $2.1 \pm 1.42$ (out of 10 ), respectively. Mann-Whitney $U$-test showed no significant statistical difference in terms of anxiety before and after the intervention between the two groups. However, according to Wilcoxon signed-rank test, there was a significant difference in terms of the mean score of anxiety before and after the intervention in the intervention and control groups $(p<0.001)$ (Table 3$)$.

\section{Discussion}

The results showed that peppermint essence aromatherapy can attenuate the pain caused by intravenous catheterization. Our search in creditable databases like ClinicalKey, Cochrane library, PubMed, and Web of Science yielded no studies on the effect of peppermint on the pain caused by intravenous catheterization. The majority of studies on the effect of inhalation aromatherapy on the pain caused by intravenous catheterization had focused on other essences like lavender in particular.

Some studies have reported about the effectiveness of aromatherapy on attenuation of the pain and anxiety caused by intravenous catheters, ${ }^{30,10}$ while some studies have argued that aromatherapy is ineffective. ${ }^{31}$ The majority of researchers have focused on the effect of peppermint essence on pain and anxiety with different causes like childbirth ${ }^{32,33}$ coronary diseases, ${ }^{21}$ stress,${ }^{34}$ post-operative pains, ${ }^{35}$ low back pain, ${ }^{36}$ neck pain, ${ }^{23}$ and test anxiety ${ }^{22}$ and reported different findings. A systematic review to survey the effect of aromatherapy on childbirth pain surveyed the articles published before 9th of November 2016. Among these articles, two were about peppermint and reported about the positive effect of the aroma on childbirth pain. ${ }^{32}$ Another study argued that Menthe piperita, citrus lemon, tea tree, and Ylang-ylang tree had a positive effect on the attenuation of stress in nurses. ${ }^{34}$ Taheri et al (2015) reported about the positive effects of peppermint essence on decreasing the pain following appendectomy operation. ${ }^{35}$ Sundstrup et al (2014) used topical gel containing menthol essence (4\%), which is a main compound in peppermint and reported that it led to a notable decrease in severity of pain in carpal tunnel syndrome patients. ${ }^{37}$ Meshgin Abadi et al (2013) tried to determine the effects of aromatherapy massage using a mixture of peppermint, celery, and lavender essences on backache in patients under Percutaneous Coronary Intervention. They reported that the intervention was effective. ${ }^{36}$ The effect of aromatic essences on neck pain using a cream containing lavender, peppermint, black pepper was studied by $\mathrm{Ou}$ et al (2014) and the results supported the effectiveness of the intervention. ${ }^{23}$ Some of the studies mentioned here used a mixture of different essences, while only pure peppermint was used in our study.

Our findings showed that peppermint essence aromatherapy can attenuate the anxiety caused by intravenous catheterization in the intervention and control groups; however, the decrease of anxiety in the control group was less than that of the intervention group. With regard to the causes of attenuation of anxiety in the control group, different psychological, physiological, and environmental factors are effective. Presence of the researcher to perform aromatherapy using distilled water can be one of the probable causes of attenuation of anxiety in the control group. The author found no studies on the effect of peppermint aromatherapy on the anxiety of intravenous catheterization. All the available studies were on other causes of anxiety-like childbirth, surgery, and exams. A clinical study reported that inhalation of peppermint essence had a significant effect on the attenuation of anxiety in heart attack patients. ${ }^{21}$ Another clinical trial showed that peppermint aromatherapy can attenuate the anxiety before colonoscopy. ${ }^{38}$ With regard to the effectiveness of inhalation of peppermint essence in attenuation of anxiety, the results of the present study are consistent with similar studies. However, some studies have argued that peppermint (pure or mixed with other essences) aromatherapy is

Table 3 Comparison Of The Anxiety Level Before And After The Intervention In Aromatherapy And Control Groups

\begin{tabular}{|c|c|c|c|c|c|c|c|}
\hline \multirow[t]{2}{*}{ Anxiety } & \multicolumn{2}{|c|}{ Aromatherapy Group } & \multicolumn{2}{|c|}{ Control Group } & \multicolumn{2}{|l|}{ Difference } & \multirow[t]{2}{*}{ Test Result $^{\mathrm{a}}$} \\
\hline & Mean \pm SD & $95 \% \mathrm{Cl}$ & Mean \pm SD & $95 \% \mathrm{Cl}$ & Mean \pm SD & $95 \% \mathrm{Cl}$ & \\
\hline Before intervention & $3.75 \pm 1.08$ & $3.405-4.095$ & $3.47 \pm 1.43$ & $3.017-3.933$ & $-0.275 \pm 0.284$ & $-0.84-0.29$ & $Z=-1.11, \mathrm{NS}$ \\
\hline After intervention & $2.32 \pm 0.97$ & $2.014-2.636$ & $2.1 \pm 1.42$ & $1.643-2.557$ & $0.225 \pm 0.273$ & $-0.769-0.319$ & $Z=-0.87, \mathrm{NS}$ \\
\hline Test result ${ }^{\mathrm{b}}$ & \multicolumn{2}{|c|}{$Z=-5.35, P<0.001$} & \multicolumn{2}{|c|}{$Z=-5.38, P<0.001$} & & & \\
\hline
\end{tabular}

Notes: ${ }^{a}$ Mann-Whitney $U$-test, ${ }^{b}$ Wilcoxon signed-rank test.

Abbreviations: $\mathrm{Cl}$, confidence interval; NS, nonsignificant; SD, standard deviation. 
not effective. A study to compare the effect of aromatherapy using lavender essence and a mixture of peppermint and orange essence on the exam anxiety in students reported that the intervention was not effective. ${ }^{22}$ Another study to compare the effect of inhalation of a lavender-sandalwood and peppermint-orange essences on the anxiety of women under breast biopsy reported that the both mixture of essence were effective. ${ }^{39}$ In terms of the effectiveness of peppermint aromatherapy, our results are consistent with mentioned studies. Chemical compounds in peppermint had strong analgesic and tranquilizing effects.

Our study was not free of limitations. As the first limitation, it was not possible to carry out a blind study as peppermint essence is aromatic and distilled water is odorless. In addition, there was a limitation in terms of homogenizing the participants in terms of age, this factor may have an influence on the patients' pain tolerance threshold.

\section{Conclusion}

Peppermint aromatherapy can attenuate the pain and anxiety caused by intravenous catheterization. Using this nonpharmacological intervention as an effective and easy method before painful and invasive procedures like intravenous catheterization is recommended. Taking into account the importance of decreasing the pain caused by injections in children, a similar study on this age group can be subject of future studies. Similar studies on other patients experiencing frequent catheterization, like patients under hemodialysis or chemotherapy are recommended. It is also suggested that future studies use the State-Trait Anxiety Inventory to measure anxiety.

\section{Data Sharing}

Data and material are available by contacting the corresponding author. In order to access the raw data, it is necessary to obtain the permission of the University Research Vice-Chancellor.

\section{Acknowledgement}

This study is part of Fatemeh Akbari's thesis to get a master's degree in nursing. We would like to express our thanks to all the patients who participated in our research, honorable nurses of internal wards of Imam Ali Hospital and deputy of research and technology of Kermanshah University of Medical Sciences. We highly appreciate the Clinical Research Development Center of Imam Reza Hospital for their wise advice.

\section{Disclosure}

The authors report no conflicts of interest in this work.

\section{References}

1. Niwa R, Koguchi A, Sonoo T. Influence of peripheral venous catheter size and resident postgraduate years on success of peripheral venous catheterization. Am $J$ Emerg Med. 2016;34(8):1716-1718. doi:10.1016/j.ajem.2016.06.016

2. Sebbane M, Claret P-G, Lefebvre S, et al. Predicting peripheral venous access difficulty in the emergency department using body mass index and a clinical evaluation of venous accessibility. J Emerg Med. 2013;44(2):299-305. doi:10.1016/j.jemermed.2012.07.051

3. Karaman T, Karaman S, Dogru S, et al. Evaluating the efficacy of lavender aromatherapy on peripheral venous cannulation pain and anxiety: a prospective, randomized study. Complement Ther Clin Pract. 2016;23:64-68. doi:10.1016/j.ctcp.2016.03.008

4. Bond M, Crathorne L, Peters J, et al. First do no harm: pain relief for the peripheral venous cannulation of adults, a systematic review and network meta-analysis. BMC Anesthesiol. 2016;16(1):81. doi:10.1186/ s12871-016-0252-8

5. Bahl A, Pandurangadu AV, Tucker J, Bagan M. A randomized controlled trial assessing the use of ultrasound for nurse-performed IV placement in difficult access ED patients. Am J Emerg Med. 2016;34 (10):1950-1954. doi:10.1016/j.ajem.2016.06.098

6. Sou V, McManus C, Mifflin N, Frost SA, Ale J, Alexandrou E. A clinical pathway for the management of difficult venous access. $B M C$ Nurs. 2017;16(1):64. doi:10.1186/s12912-017-0263-x

7. Parker SI, Benzies KM, Hayden KA, Lang ES. Effectiveness of interventions for adult peripheral intravenous catheterization: a systematic review and meta-analysis of randomized controlled trials. Int Emerg Nurs. 2017;31:15-21. doi:10.1016/j.ienj.2016.05.004

8. Palese A, Ambrosi E, Fabris F, et al. Nursing care as a predictor of phlebitis related to insertion of a peripheral venous cannula in emergency departments: findings from a prospective study. $J$ Hosp Infect. 2016;92(3):280-286. doi:10.1016/j.jhin.2015.10.021

9. Ghods AA, Abforosh NH, Ghorbani R, Asgari MR. The effect of topical application of lavender essential oil on the intensity of pain caused by the insertion of dialysis needles in hemodialysis patients: a randomized clinical trial. Complement Ther Med. 2015;23(3):325330. doi:10.1016/j.ctim.2015.03.001

10. Cho S-Y, Kim E, Park S-H, et al. Effect of topical anesthesia on pain from needle insertion and injection and its relationship with anxiety in patients awaiting apical surgery: a randomized double-blind clinical trial. J Endod. 2017;43(3):364-369. doi:10.1016/j.joen.2016.10.036

11. Nasiri A, Mahmodi MA. Aromatherapy massage with lavender essential oil and the prevention of disability in ADL in patients with osteoarthritis of the knee: a randomized controlled clinical trial. Complement Ther Clin Pract. 2018;30:116-121. doi:10.1016/j.ctcp.2017.12.012

12. Keyhanmehr AS, Kolouri S, Heydarirad G, Mofid B, Mosavat SH. Aromatherapy for the management of cancer complications: a narrative review. Complement Ther Clin Pract. 2018;31:175-180. doi:10.1016/j.ctcp.2018.02.009

13. Yayla EM, Ozdemir L. Effect of inhalation aromatherapy on procedural pain and anxiety after needle insertion into an implantable central venous port catheter: a quasi-randomized controlled pilot study. Cancer Nurs. 2017. doi:10.1097/NCC.0000000000000551

14. Metin ZG, Ozdemir L. The effects of aromatherapy massage and reflexology on pain and fatigue in patients with rheumatoid arthritis: a randomized controlled trial. Pain Manage Nurs. 2016;17(2):140149. doi:10.1016/j.pmn.2016.01.004

15. Bouya S, Ahmadidarehsima S, Badakhsh M, Balouchi A, Koochakzai M. Effect of aromatherapy interventions on hemodialysis complications: a systematic review. Complement Ther Clin Pract. 2018;32:130-138. doi:10.1016/j.ctcp.2018.06.008 
16. Hamdamian S, Nazarpour S, Simbar M, Hajian S, Mojab F, Talebi A Effects of aromatherapy with Rosa damascena on nulliparous women's pain and anxiety of labor during first stage of labor. $J$ Integr Med. 2018;16(2):120-125. doi:10.1016/j.joim.2018.02.005

17. Gnatta JR, Kurebayashi LFS, Turrini RNT, Silva M. Aromatherapy and nursing: historical and theoretical conception. Rev Esc Enferm USP. 2016;50(1):127-133. doi:10.1590/S0080-62342016000010 0017

18. Mahboubi M. Mentha spicata as natural analgesia for treatment of pain in osteoarthritis patients. Complement Ther Clin Pract. 2017;26:1-4. doi:10.1016/j.ctcp.2016.11.001

19. Mahboubi M. Mentha spicata L. essential oil, phytochemistry and its effectiveness in flatulence. J Tradit Complement Med. 2018. doi:10.1016/j.jtcme.2017.08.011

20. Heshmati A, Dolatian M, Mojab F, Nikkhah S, Mahmoodi Z. The effect of peppermint (Mentha piperita) capsules on the severity of primary dysmenorrhea. J Herb Med. 2016;6(3):137-141. doi:10.1016/j.hermed.2016.05.001

21. Vaezi A, Parizi S, Vahidi A, Tavangar H. Study the effect of inhalation of peppermint oil on depression and anxiety in patients with myocardial infarction who are hospitalized in intensive care units of Sirjan. J Med Plants. 2017;2(62):55-62.

22. Lipschultz A, Downey M, Willhaus J, Siemon M, Bond L. The use of aromatherapy to reduce test anxiety among nursing students. 2016.

23. Ou M-C, Lee Y-F, Li -C-C, Wu S-K. The effectiveness of essential oils for patients with neck pain: a randomized controlled study. $J$ Altern Complement Med. 2014;20(10):771-779. doi:10.1089/ acm.2013.0453

24. Bagheri-Nesami M, Espahbodi F, Nikkhah A, Shorofi SA, Charati JY. The effects of lavender aromatherapy on pain following needle insertion into a fistula in hemodialysis patients. Complement Ther Clin Pract. 2014;20(1):1-4. doi:10.1016/j.ctcp.2013.11.005

25. Bourdel N, Alves J, Pickering G, Ramilo I, Roman H, Canis M. Systematic review of endometriosis pain assessment: how to choose a scale? Hum Reprod Update. 2015;21(1):136-152. doi:10.1093/ humupd/dmu046

26. Bailly F, Fautrel B, Gossec L. Pain assessment in rheumatology how can we do better? A literature review. Joint Bone Spine. 2016;83 (4):384-388. doi:10.1016/j.jbspin.2016.01.001

27. Abend R, Dan O, Maoz K, Raz S, Bar-Haim Y. Reliability, validity and sensitivity of a computerized visual analog scale measuring state anxiety. J Behav Ther Exp Psychiatry. 2014;45(4):447-453. doi:10.1016/j.jbtep.2014.06.004
28. Facco E, Stellini E, Bacci C, et al. Validation of visual analogue scale for anxiety (VAS-A) in preanesthesia evaluation. Minerva Anestesiol. 2013;79(12):1389-1395.

29. Tanaka N, Ohno Y, Hori M, et al. Predicting preoperative hemodynamic changes using the visual analog scale. J Perianesth Nurs. 2015;30(6):460-467. doi:10.1016/j.jopan.2014.02.005

30. Bikmoradi A, Khaleghverdi M, Seddighi I, Moradkhani S, Soltanian A, Cheraghi F. Effect of inhalation aromatherapy with lavender essence on pain associated with intravenous catheter insertion in preschool children: a quasi-experimental study. Complement Ther Clin Pract. 2017;28:85-91. doi:10.1016/j.ctcp.2017.05.008

31. Grunebaum LD, Murdock J, Castanedo-Tardan MP, Baumann LS Effects of lavender olfactory input on cosmetic procedures. J Cosmet Dermatol. 2011;10(2):89-93. doi:10.1111/j.1473-2165.2011.00554.x

32. Ghiasi A, Hasani M, Mollaahmadi L, Hashemzadeh M, Haseli A. The effect of aromatherapy on labor Pain relief: a systematic review of clinical trials. IJOGI. 2017;20(2):89-105.

33. Ozgoli G, Torkashvand S, Salehi Moghaddam F, Borumandnia N, Mojab F, Minooee S. Comparison of peppermint and clove essential oil aroma on pain intensity and anxiety at first stage of labor. IJOGI. 2016;19(21):1-11.

34. Seo E-Y, Song J-A, Hur M-H, Lee M-K, Lee MS. Effects of aroma mouthwash on stress level, xerostomia, and halitosis in healthy nurses: a non-randomized controlled clinical trial. Eur J Integr Med. 2017;10 (Supplement C):82-89. doi:10.1016/j.eujim.2017.03.001

35. Shahdadi H, Balouchi A, Taheri S, Darban F. Study effect of mint essence on pain, bloat and nausea in patients undergoing appendectomy. Pharm Lett. 2015;7(10):193-197.

36. Meshgin Abadi N, Ramezani Badr F, Mahmoodi K. The use of aromatherapy massage to reduce backpain after Percutaneous Coronary Intervention (PCI): a semi-experimental study. ZUMS J. 2013;21(86):24-34.

37. Sundstrup E, Jakobsen MD, Brandt M, et al. Acute effect of topical menthol on chronic pain in slaughterhouse workers with carpal tunnel syndrome: triple-blind, randomized placebo-controlled trial. Rehabil Res Pract. 2014;2014. doi:10.1155/2014/310913

38. Mogharab M, Ayoubzadeh K, Sharif-Zadeh GR. Effect of peppermint aromatherapy on the level of anxiety in patients undergoing colonoscopy. Medsurg Nurs J. 2017;6(1):41-50.

39. Trambert R, Kowalski MO, Wu B, Mehta N, Friedman P. A randomized controlled trial provides evidence to support aromatherapy to minimize anxiety in women undergoing breast biopsy. Worldviews Evid Based Nurs. 2017;14(5):394-402. doi:10.1111/wvn.12229
Journal of Pain Research

\section{Publish your work in this journal}

The Journal of Pain Research is an international, peer reviewed, open access, online journal that welcomes laboratory and clinical findings in the fields of pain research and the prevention and management of pain. Original research, reviews, symposium reports, hypothesis formation and commentaries are all considered for publication. The manuscript

Submit your manuscript here: https://www.dovepress.com/journal-of-pain-research-journal management system is completely online and includes a very quick and fair peer-review system, which is all easy to use. Visit http:// www.dovepress.com/testimonials.php to read real quotes from published authors. 